\title{
O JUÍZO DE ADMISSIBILIDADE DO INCIDENTE DE RESOLUÇÃO DE DEMANDAS REPETITIVAS: CRÍTICA A AUSÊNCIA DE CONTRADITÓRIO EM FACE DA SOCIEDADE DA INFORMAÇÃO.
}

\author{
Daiane Moura de Aguiar* \\ Augusto Rodrigues Porciuncula**
}

Resumo: O presente artigo busca investigar a necessidade de manifestação prévia das partes antes do juízo de admissibilidade do Incidente de Resolução de Demandas Repetitivas, ou seja, verificar as implicações da ausência de previsão legal do contraditório e a possibilidade de adequação legislativa ou jurisprudencial desta omissão legislativa. A partir desta análise, chega-se a conclusão que a valorização do instituto na sociedade da informação, em especial, pela celeridade do processo eletrônico e necessidade da efetiva utilização dos bancos de dados dos Tribunais Superiores, somente será alcançada com a efetiva participação das partes no juízo de admissibilidade mediante a oportunidade do contraditório.

Palavras-Chaves: Processo Civil - Incidente de Resolução de Demandas Repetitivas Admissibilidade - Contraditório - Sociedade da Informação.

\section{THE ADMISSIBILITY JUDGMENT OF THE INCIDENT OF RESOLUTION OF REPETITIVE DEMANDS: CRITIQUE THE ABSENCE OF CONTRADICTORY IN THE FACE THE INFORMATION SOCIETY.}

Abstract: This article intends to investigate about the preview manifestation of the litigants before the admissibility of the Incident of Resolution of Repetitive Demands and verify the implications of the legislative omission. From this analysis, it is possible conclude that the importance of institute in Information Society will only be achieved with the effective participation of the opponent.

Key-Words: Civil Lawsuit - Incident of Resolution of Repetitive Demands - Admissibility

- Contradictory - Information Society

\section{INTRODUÇÃO}

Os sistemas de resolução de demandas repetitivas, inaugurado pela Súmula Vinculante e os recursos repetitivos, visam, em linhas gerais, fixar teses jurídicas com o objetivo de conferir maior segurança jurídica, racionalidade e celeridade na prestação

\footnotetext{
*Doutora em Direito Púbico pela Universidade do Vale do Rio dos Sinos. Mestre em Direito Público pela Universidade do Vale do Vale do Rio dos Sinos. Professora da Universidade Anhembi Morumbi. Advogada. https://orcid.org/0000-0001-9192-5591. daianemouradeaguiar@ gmail.com

**Mestrando em Direito da Sociedade da Informação do Centro Universitário das Faculdades Metropolitanas Unidas - FMU. Especialista em Direito Empresarial pela PUC/RS. Procurador do Estado de São Paulo. https://orcid.org/0000-0002-9999-5460. arporciuncula@yahoo.com.br
} 
jurisdicional. O Novo Código de Processo Civil trouxe a previsão do Incidente de Resolução de Demandas Repetitivas (IRDR) como instrumento jurídico também destinado a fixar teses jurídicas, inclusive, a própria Exposição de Motivos relata esse objetivo e a inspiração no procedimento-modelo alemão. Todavia, diante de sua novidade no sistema processual brasileiro existem mais dúvidas do que certezas quanto ao correto uso do instrumento, sua constitucionalidade, a efetiva entrega da prestação jurisdicional, sendo, portanto, indispensável a participação acadêmica para a sua efetiva consolidação.

A legislação processual prevê duas fases distintas no trâmite do Incidente de Resolução de Demandas Repetitivas: juízo de admissibilidade (cabimento) e juízo de mérito (fixação de tese jurídica). No presente artigo, sem jamais pretender esgotar a discussão, é analisado o juízo de admissibilidade do incidente, em especial, as repercussões decorrentes da ausência de previsão legal do contraditório. Gize-se que a análise é realizada nesta fase inaugural, levando em consideração eventual juízo que possa repercutir na esfera jurídica dos litigantes.

Com efeito, o estudo é desenvolvido dentro do contexto da sociedade da informação onde ocorre o amplo acesso ao processo eletrônico, ao acervo doutrinário disponível na rede mundial de computadores e aos bancos de dados dos Tribunais Superiores. Dessa forma, as questões envolvendo celeridade e efetividade processual são observadas no atual estágio do avanço da tecnologia da informação.

A metodologia adotada é a bibliográfica, utilizando-se referencial teórico doutrinário a respeito da implantação do instituto do Incidente de Resolução de Demandas Repetitivas no sistema processual brasileiro. Da mesma forma, exemplifica-se o uso do incidente de resolução de demandas repetitivas, por meio de alguns casos oriundos do Tribunal de Justiça de São Paulo.

\section{O Incidente de Resolução de Demandas Repetitivas.}

O incidente de resolução de demandas repetitivas (IRDR) está previsto no art. 976 e ss. do NCPC, com a seguinte redação: 


\section{O JUÍZO DE ADMISSIBILIDADE DO INCIDENTE DE RESOLUÇÃO DE DEMANDAS REPETITIVAS: CRÍTICA A AUSÊNCIA DE CONTRADITÓRIO EM FACE DA SOCIEDADE DA INFORMAÇÃO}

Art. 976. É cabível a instauração do incidente de resolução de demandas repetitivas quando houver, simultaneamente:

I - efetiva repetição de processos que contenham controvérsia sobre a mesma questão unicamente de direito;

II - risco de ofensa à isonomia e à segurança jurídica.

O objetivo desse incidente processual é conferir um julgamento coletivo e abstrato, viabilizando a aplicação vinculada da tese jurídica aos casos concretos (presentes e futuros) em tramitação na competência territorial do órgão julgado e, em tese, atender aos princípios da segurança jurídica, da isonomia e da economia processual. Trata-se de mecanismo processual proposto para uniformização e fixação de tese jurídica repetitiva que passará a vincular todos os outros casos por ele afetados.

Castro Mendes (2017) aponta que os instrumentos processuais típicos para a tutela de pretensões individuais se revelaram inadequados para solucionar a multiplicidade de ações decorrentes das atuais relações massificadas e que, portanto, o legislador brasileiro desenvolveu o Incidente de Resolução de Defendas Repetitivas baseado fundamentalmente no procedimento-modelo alemão (Musterverfahren). Nas palavras de Castro Mendes (2017, p.7):

Neste contexto, a primeira afirmação que se procura desenvolver neste trabalho
é no sentido de que o novo Incidente de Resolução de Demandas Repetitivas
está inserido no âmbito do Direito Processual Coletivo. Este ramo, por sua vez,
pode ser subdividido em três subáreas: a) as ações coletivas ou representativas
propriamente ditas, incluindo as suas várias subespécies, como as class actions,
as ações associativas (Verbandsklagen), ação civil pública, ação popular, ações
de grupo etc.; b) os meios consensuais de resolução de conflitos coletivos, como
os termos de ajustamento de conduta; c) os instrumentos de solução de questões
comuns ou de julgamentos a partir de procedimentos ou casos-modelo, como as
test-claims (ações ou demandas teste), o Musterverfahren (procedimento-
modelo), o Group Litigation Order (GLO) (Decisão sobre o litígio de grupo), os
recursos repetitivos e o Incidente de Resolução de Demandas Repetitivas
(IRDR).

No mesmo sentido, Bueno (2016, p.367) define que o objetivo principal do instituto é o de obter decisões iguais para casos (predominantemente) iguais, sendo vocacionado a desempenhar, na tutela daqueles princípios, da isonomia e da segurança jurídica, papel próximo (e complementar) ao dos recursos extraordinários e especiais repetitivos. A própria exposição de motivos do Novo Código de Processo Civil (2015) relata que o Incidente de Resolução de Demandas Repetitivas teve inspiração no procedimento-modelo alemão (Musterverfahren): 
Dentre esses instrumentos, está a complementação e o reforço da eficiência do regime de julgamento de recursos repetitivos, que agora abrange a possibilidade de suspensão do procedimento das demais ações, tanto no juízo de primeiro grau, quanto dos demais recursos extraordinários ou especiais, que estejam tramitando nos tribunais superiores, aguardando julgamento, desatreladamente dos afetados. Com os mesmos objetivos, criou-se, com inspiração no direito alemão, o já referido incidente de Resolução de Demandas Repetitivas, que consiste na identificação de processos que contenham a mesma questão de direito, que estejam ainda no primeiro grau de jurisdição, para decisão conjunta. Em linhas gerais, o Incidente de Resolução de Demandas repetitivas é admissível quando identificada controvérsia com potencial de gerar multiplicação expressiva de demandas e o correlato risco da coexistência de decisões conflitantes.

Diga-se, todavia, que a doutrina, podendo ser citado Viafore $(2013$, p. 257) e Mancuso (2016, p. 187), critica essa inspiração no modelo alemão, pois as diferenças quando da positivação no sistema processual brasileiro importam em enorme distanciamento do modelo alemão. Não será abordada estas semelhanças e diferenças no presente trabalho pois fogem do objeto de estudo.

Com efeito, o incidente é uma técnica processual destinada para a litigiosidade repetitiva e se fundamenta em três pilares: o princípio constitucional da isonomia (tratamento uniforme dos litígios isomorfos); a segurança jurídica, (previsibilidade e uniformidade das decisões); prestação jurisdicional em tempo razoável (CASTRO MENDES e TEMER. 2016, p. 1271).

O legislador, com objetivo de instrumentalizar o incidente, previu duas fases distintas no procedimento: o juízo de admissibilidade - onde são verificados os requisitos legais para a tramitação - e, em momento posterior, uma vez admitido, o juízo de mérito quando é definida a tese jurídica a ser aplicada. A competência para ambas é, nos termos do art. 978 do NCPC (2015), do “órgão indicado pelo regimento interno dentre aqueles responsáveis pela uniformização de jurisprudência do tribunal".

No presente trabalho será analisada apenas a primeira fase, ou seja, o juízo de admissibilidade e a omissão legislativa quanto a participação das partes, pois no tocante ao juízo de mérito, nos termos dos art. 982 e seguintes do NCPC, há a preocupação da publicização da tramitação do incidente e expressa previsão de participação das partes (e terceiros interessados) no julgamento através de manifestação nos autos e audiências públicas. 


\section{O JUÍZO DE ADMISSIBILIDADE DO INCIDENTE DE RESOLUÇÃO DE DEMANDAS REPETITIVAS: CRÍTICA A AUSÊNCIA DE CONTRADITÓRIO EM FACE DA SOCIEDADE DA INFORMAÇÃO}

\section{O juízo de admissibilidade do Incidente de Resolução de Demandas Repetitivas.}

Antes da apreciação do mérito da discussão da resolução de demandas repetitivas e a fixação da tese jurídica, a legislação prevê um juízo exclusive de admissão, onde será verificada a presença dos requisitos legais. Dispõe o art. 981 do Código de Processo Civil que "após a distribuição, o órgão colegiado competente para julgar o incidente procederá ao seu juízo de admissibilidade, considerando a presença dos pressupostos do art. 976.”

Conforme já apontado, os requisitos estão previstos no já citado art. 976 do Código de Processo Civil, ao estabelecer que o Incidente de Resolução de Demandas Repetitivas é cabível quando, simultaneamente, (i) houver efetiva repetição de processos que contenham controvérsia sobre a mesma questão de direito e (ii) risco de ofensa à isonomia e à segurança jurídica. Nesta fase de admissibilidade, o órgão julgador fica adstrito a análise da presença, ou não, destes requisitos para instauração do Incidente.

A primeira importante observação a respeito é a necessidade da efetiva repetição de processos. O texto legal não estabelece objetivamente um número (quantidade) de processos para caracterizar uma efetiva repetição, sendo um conceito aberto e indeterminado para a doutrina e a jurisprudência definir os contornos. Por sua vez, mesmo sem exigência legal da existência de milhares de decisões judiciais, a mera potencialidade de repetição de processos não satisfaz o requisito legal, sendo imprescindível a aferição concreta desta repetição de causas isomorfas, sob pena de desconfigurar o instituto para um juízo abstrato de legalidade.

Conforme aponta Cavalcanti (2016), o texto legal incorporou as críticas apresentadas em face de eventual caráter preventivo do incidente e restou definido que o instituto somente terá cabimento quando já estiverem em tramitação diversos processos. A efetiva repetição de processos deve ser analisada em conjunto com o segundo requisito legal previsto no artigo 976 do Novo Código de Processo Civil, qual seja, o risco de decisões conflitantes.

Com efeito, a quantidade de processos repetitivos deve ser de ordem tamanha a caracterizar um 'risco de ofensa à isonomia e à segurança jurídica'. Nesse sentido, o enunciado no 87 do Fórum Permanente de Processualistas, aprovado na reunião realizada em Salvador (08-09 de novembro de 2013), afirma que “a instauração do incidente de resolução 
de demandas repetitivas não pressupõe a existência de grande quantidade de processos versando sobre a mesma questão, mas preponderantemente o risco de quebra da isonomia e de ofensa à segurança jurídica”.

Destaca-se, ainda, que a questão deve ser unicamente de direito. Aponta Castro Meira (2017) que a discussão poderá ser material ou processual, mas a mera identidade apenas fática não autoriza, pois, o objetivo do legislador foi limitar apenas que as questões de direito poderão ser definidas no incidente, com a respectiva fixação da tese jurídica a ser aplicada uniformemente.

Quanto ao segundo requisito, o texto legal é expresso ao exigir a existência de 'risco de ofensa à isonomia e à segurança jurídica', todavia até o momento tem se relegado este requisito e outorgado excessiva relevância para a existência de repetição de processos com controvérsia idêntica sobre questão de direito. De toda sorte, não basta que haja a controvérsia entre partes, mas que esta esteja efetivamente ensejando divergência no seio do Poder Judiciário, capaz de comprometer, de fato, o princípio da isonomia e da segurança jurídica.

Por fim, a legislação apresenta um requisito negativo: a questão não este já afetada em recurso especial ou extraordinário repetitivo (art. 976, §4º ${ }^{\circ}$ do CPC). Tal situação ganha relevância na Sociedade da Informação, na medida em que a correta alimentação e o efetivo uso dos bancos de dados dos Tribunais Superiores (STF e STJ) e do próprio Conselho Nacional de Justiça são indispensáveis para a aferição deste requisito negativo da admissão do Incidente de Resolução de Demandas Repetitivas.

Além disso, se extrai exclusivamente do texto legal, art. 977 NCPC, a legitimidade para propor o incidente, o juiz ou relator (por ofício), as partes, o Ministério Público e a Defensoria Pública (por petição). Nesse ponto, destaca-se o posicionamento de Cavalcanti (2016, p. 253):

A legitimação autônoma para condução do IRDR é concorrente e disjuntiva. Isto é, a legitimidade de um dos legitimados não exclui a de outro. Todos são simultaneamente legitimados para agir (legitimação concorrente). Ao mesmo tempo, qualquer um deles pode atuar, sozinho, em juízo, sem a necessidade de formar litisconsórcio ou autorizar outro habilitado (legitimação disjuntiva). 


\section{O JUÍZO DE ADMISSIBILIDADE DO INCIDENTE DE RESOLUÇÃO DE DEMANDAS REPETITIVAS: CRÍTICA A AUSÊNCIA DE CONTRADITÓRIO EM FACE DA SOCIEDADE DA INFORMAÇÃO}

Soma-se a isso, a possibilidade de vários legitimados suscitarem o IRDR perante o mesmo tribunal. Nesse caso, de acordo com o Enunciado 89 do Fórum Permanente de Processualistas Civis há a necessidade de julgamento conjunto de todo:

Havendo apresentação de mais de um pedido de instauração do incidente de resolução de demandas repetitivas perante o mesmo tribunal todos deverão ser apensados e processados conjuntamente; os que forem oferecidos posteriormente à decisão de admissão serão apensados e sobrestados, cabendo ao órgão julgador considerar as razões neles apresentadas.

Quanto a legitimidade, é importante destacar a crítica de parte da doutrina ao texto legal que não observou a necessidade de representação adequada. Cita-se, por exemplo, a posição de Marinoni (2016, p.41):

No direito brasileiro, quando em jogo direitos individuais homogêneos, é
impossível pensar em excluir o representante adequado, sob pena de violação
ao devido processo legal. Portanto, o incidente de resolução de demandas
deveria ter previsto, nos moldes da tradição do direito brasileiro, a
participação dos legitimados adequados à tutela dos direitos dos litigantes
excluídos. Contudo, o incidente nada previu em termos de representação
adequada. Como já dito, o legislador partiu da premissa de que o incidente
não estaria a resolver questão da titularidade dos litigantes das demandas
repetitivas, mas simplesmente a abrir oportunidade à elaboração de
precedente obrigatório (art. 927 , III, do CPC/2015) sobre questão de direito -
curiosamente do interesse dos litigantes excluídos.

E segue ao afirmar que, nos termos em que está posto pelo Código de Processo Civil, acaba por negar o direito fundamental de ação e gera uma espécie de "justiça dos cidadãos sem rosto e fala", para a qual pouco importa saber se há participação ou, ao menos, "representação adequada". (MARINONI, 2016, p. 43). Tal questão reforça o objeto do presente estudo, a necessidade de um contraditório prévio a própria admissibilidade do Incidente onde questões como pertinência e legitimidade poderiam ser suscitadas pela parte adversa.

Dentro dessa linha, destaca que a legislação é omissa quanto a oitiva das partes (seja no incidente instaurado de ofício ou por petição) antes do juízo de admissibilidade, apesar da legislação ser extremamente rigorosa na exigência dos requisitos positivos e negativos para admissão. Oportuno, desde já, apontar que o Direito à Informação e próprio Acesso à Informação, constitucionalmente previstos, não são garantidos nesta fase de 
admissibilidade diferindo-se apenas para após ao juízo positivo a divulgação e publicidade da existência do Incidente de Resolução de Demanda Repetitivas.

Inclusive, tal diferimento é preocupante na medida em que a admissão do incidente (mesmo sem a participação dos envolvidos) já repercute na esfera jurídicoprocessual. O art. 982, I do Código de Processo Civil expressamente aponta a suspensão dos processos relacionados ao tema objeto do incidente:

Art. 982. Admitido o incidente, o relator:

I - suspenderá os processos pendentes, individuais ou coletivos, que tramitam no Estado ou na região, conforme o caso;

O mencionado artigo ao dispor que o relator deve determinar, por meio de decisão, a suspensão dos processos repetitivos pendentes, deve ser analisado em conjunto com art. 313, IV do CPC, ou seja, a própria decisão de admissibilidade do incidente tem a eficácia suspensiva desejada pelo legislador. Conforme explica Cavalcanti (2016), a principal consequência da decisão da admissibilidade é a suspensão automática da tramitação dos processos repetitivo, cabendo ao relator do incidente apenas comunicar tal decisão aos órgãos jurisdicionais. Assim, o juízo de admissibilidade gera efeitos os quais, como aqui se defende, deveriam ser objeto de contraditório prévio.

Não se desconhece que, ao arrepio da norma cogente, a jurisprudência tem mitigado está determinação legal para a suspensão. Pode-se citar alguns precedente do Tribunal de Justiça de São Paulo (IRDR n ${ }^{\circ}$ 0023203-35.2016.8.26.0000, IRDR N ${ }^{\circ}$ 2151535-83.2016.8.26.0000, IRDR n ${ }^{\text {o } 2243516-62.2017 .8 .26 .0000) ~ o n d e ~ c o n s t o u ~ d o ~ v o t o ~}$ do Desembargador Relator: "O voto é pela admissão do incidente de resolução de demandas repetitivas, sem suspensão dos processos em primeiro ou segundo grau"

Todavia, não obstante tais situações (as quais não será objeto da presente discussão a congruência da decisão), o texto legal determina a suspensão dos feitos pendentes mesmo sem a participação ativa das partes no juízo de admissibilidade, através do regular contraditório. Por fim, cumpre apenas destacar que o juízo de admissibilidade deve ser realizado pelo órgão colegiado (art. 981, CPC), sendo vedado eventual juízo monocrático do Relator designado. Ademais, não se vislumbra a recorribilidade do acórdão (ressalvado eventual Embargos de Declaração, nos limites de sua cognição) eis que, sendo 


\section{O JUÍZO DE ADMISSIBILIDADE DO INCIDENTE DE RESOLUÇÃO DE DEMANDAS REPETITIVAS: CRÍTICA A AUSÊNCIA DE CONTRADITÓRIO EM FACE DA SOCIEDADE DA INFORMAÇÃO}

apenas juízo de admissibilidade não se verifica o enquadramento na exigência de "causa decidida" prevista nos art. 102, III e 105, III, da Constituição Federal para o manejo dos recursos especial e extraordinário respectivamente.

Dessa forma, mesmo que apresentado de forma superficial, verifica-se que o juízo de admissibilidade do Incidente de Resolução de Demandas Repetitivas depende do exame de diversos requisitos (positivos e negativos) e, em caso de admissão, são gerados efeitos imediatos na esfera processual das partes, inclusive com a preclusão da discussão.

\section{A necessidade de contraditório prévio ao juízo de admissibilidade.}

Conforme já apontado, o objeto do presente artigo é exatamente investigar a necessidade de oitiva das partes prévia ao juízo de admissibilidade. O procedimento do Incidente de Resolução de Demandas Repetitivas é bifásico. Em um primeiro momento, haverá a apreciação da sua admissibilidade. No segundo, caso superado o primeiro, ocorrerá o julgamento propriamente dito da questão jurídica suscitada, com a formulação da tese jurídica vinculativa.

O Código de Processo Civil não estabeleceu um procedimento ou contraditório prévio específico em relação à admissibilidade. Castro Meira, destaca que:

não há, antes da sessão do julgamento, sequer oportunidade específica para que as partes, interessados e o próprio Ministério Público possam se manifestar sobre a admissibilidade do IRDR. É claro que isto não impede que sejam apresentadas petições ou manifestações sobre o juízo de admissibilidade. Contudo, não há porque se privar do contraditório mínimo sobre a admissibilidade e outros aspectos decorrentes, como a própria suspensão de processos relacionados, para que as partes, os interessados e o Ministério Público possam fazer uso da palavra, em sintonia com o previsto no art. 984 do CPC.” (2017, p. 172)

Ocorre, todavia, diverso da solução apontada pelo autor, tem-se que o Contraditório e a Ampla Defesa são princípios constitucionais expressamente previstos na Carta Magna de 1988 (art. 5. $\mathrm{LV}$ - aos litigantes, em processo judicial ou administrativo, e aos acusados em geral são assegurados o contraditório e a ampla defesa, com os meios e recursos a ela inerentes), e a sua plena observância e respeito são requisitos indispensáveis ao devido processo legal e segurança jurídica. Conforme leciona Santos:

Tradicionalmente, o princípio do contraditório possui como conteúdo $(i)$ o direito à informação ou à comunicação dos atos processuais e (ii) a possibilidade de impugnação, de reação ou de manifestação. Ambos possuem aspectos

Rev. de Processo, Jurisdição e Efetividade da Justiça | e-ISSN: 2525-9814 | Porto Alegre | v. 4 | n. 2 | p. $115-129$ | Jul/Dez. 2018 
meramente formais e restringem sua aplicação tão somente às partes, de modo que o órgão jurisdicional não seria submetido ao princípio do contraditório, devendo apenas velar pela aplicação do princípio entre as partes, que seriam exclusivamente os seus destinatários. Contemporaneamente, em um Estado Constitucional, Democrático e de Direito, o princípio do contraditório possui também outros conteúdos, não só os meramente formais. Além dos direitos à comunicação dos atos processuais e à manifestação, também integram o princípio do contraditório os direitos à participação no desenvolvimento do processo, à influência no conteúdo das decisões judiciais, das partes de terem seus argumentos considerados e de não serem surpreendidas com a prolação de decisão surpresa. O princípio, assim, indubitavelmente, ganha aspectos substanciais. (2018.p.78)

Exatamente em relação a este aspecto substancial do contraditório que se verifica a inconstitucionalidade por omissão do regramento do Incidente de Resolução de Demanda Repetitivas. A possibilidade de manifestação da parte não é meramente formal e deve ser concedida em momento adequado e de forma eficiente, de modo a viabilizar a influência no resultado, garantindo-se as partes o direito de ter seus argumentos considerados na decisão jurisdicional e impedindo uma decisão surpresa.

Segundo Santos (2018), decisão surpresa é aquela que contém como fundamento matéria de fato ou de direito que não tenha sido previamente oportunizada, em nenhum momento processual, a manifestação dos sujeitos processuais a seu respeito.

O processo é a institucionalização do jogo da argumentação, estando intrinsecamente relacionada ao princípio do contraditório, de modo a assegurar às partes condições para trazer ao juízo todos os elementos necessários ao processo decisório. A soma da parcialidade das partes, num processo dialético conduz o juiz à síntese, de modo que a ação disjuntiva, mas combinada, tende a auxiliar na eliminação do conflito que as envolve (CINTRA, GRINOVER e DINAMARCO, 2014).

No entender de Silveira (1997, p. 62), “o contraditório foi elevado à condição de fundamento constitucional de todo e qualquer procedimento, judicial ou administrativo, sendo indevida qualquer restrição". Dessa forma, o fim último do contraditório é assegurar o democrático jogo de inteligências, garantindo simetria (igualdade de armas), possibilidade de intervenção e controle do arbítrio judicial, deixando o juiz de ser mero espectador do processo, mas verdadeiro agente condutor da participação das partes.

No caso específico do Incidente de Resolução de Demandas Repetitivas, analisado dentro do atual contexto da Sociedade da Informação, verifica-se que a oportunidade das 


\section{O JUÍZO DE ADMISSIBILIDADE DO INCIDENTE DE RESOLUÇÃO DE DEMANDAS REPETITIVAS: CRÍTICA A AUSÊNCIA DE CONTRADITÓRIO EM FACE DA SOCIEDADE DA INFORMAÇÃO}

partes se manifestarem não traz prejuízo a razoável duração do processo, bem como, tende a qualificar o juízo decisório na medida em que as partes tem franco acesso aos bancos de dados dos Tribunais Superiores e a produção doutrinária.

No que tange a ausência de prejuízo a celeridade processual, o Processo Eletrônico, as intimações via Diário Eletrônico e a rapidez no trâmite (juntada) das peças processuais no processo digital permitem a participação das partes no juízo de admissibilidade em tempo razoável. As ferramentas de tecnologia da informação e comunicação disponíveis para a conexão quase que instantânea entre o jurisdicionado (devidamente representado nos autos) e o Poder Judiciário afastam eventual morosidade na concessão de prazo razoável a manifestação antes do juízo de admissibilidade.

Dentro, ainda, da questão da razoável duração do processo, verifica-se que o art. 980 do CPC prevê o prazo de 1 (hum) ano para julgamento do mérito do Incidente após a admissão. Considerando tal prazo apontado na legislação, não se pode concordar com eventual alegação de que a manifestação prévia das partes poderá por em risco a celeridade processual, pois com os meios tecnológicos e realidade da virtualização do processo judicial, eventual contraditório prévio importaria, no máximo, em mais 30 (trinta) dias de tramitação processual, o que não representa prejuízo substancial ou ofensa a celeridade.

Outro aspecto também deve ser considerado na Sociedade da Informação, o amplo acesso aos dados e ao conhecimento permitem que a participação de todos os atores processuais qualifique o debate. Trata-se da efetivação dos preceitos constitucionais do Direito à Informação e Acesso à Informação, de modo que a parte poderá trazer maiores elementos para a cognição judicial.

Cita-se, por exemplo, a exigência legal (requisito negativo de admissibilidade, supra apresentado) de inexistir matéria idêntica afetada ao julgamento de demandas repetitivas no Superior Tribunal de Justiça e Supremo Tribunal Federal. Ambos tribunais mantêm base de dados (temas) disponíveis para a pesquisa em seus respectivos endereços eletrônicos, todavia o número de matérias afetadas já alcança a casa dos milhares, motivo pelo qual a participação das partes tende a auxiliar o Poder Judiciário a depurar a informação. 
Assim, evidencia que a efetiva participação das partes antes do juízo de admissibilidade importa em medida ágil, útil e necessária para a melhor decisão judicial possível, bem como, evita o risco de repercussão na esfera processual (suspensão dos processos) em hipótese não compreendida no texto legal.

Como reforço de argumentação, é importante destacar que o legislador, para a fase de julgamento (após a admissão), expressamente previu a participação das partes na fixação da tese jurídica, garantindo-se a manifestação nos autos, a participação nas audiências públicas e na sessão de julgamento. Ademais, em situação excepcional no ordenamento jurídico concedeu ao terceiro interessado (amicus curiae) amplos poderes de participação processual, inclusive capacidade recursal. Disserta Santos (2018, p. 212):

Como se vê, a intenção do incidente é preservar o princípio constitucional da isonomia, ao garantir igualdade de solução para os jurisdicionados que se encontrem na mesma situação fática e jurídica, conferindo força ao precedente judicial.Por esta razão, o art. 983 prevê que o relator poderá ouvir "interessados, inclusive pessoas, órgãos e entidades com interesse na controvérsia", que podem, no prazo de quinze dias, "requerer a juntada de documentos, bem como as diligências necessárias para a elucidação da questão de direito controvertida". Trata-se, indubitavelmente, de previsão que diz respeito à participação do amicus curiae no incidente, em exercício de contraditório institucionalizado. $\mathrm{O}$ interesse na controvérsia previsto no texto só pode ser entendido como interesse institucional. Como o amicus curiae tem a função de legitimar socialmente as decisões proferidas pelo Poder Judiciário, a sua participação no Incidente de Resolução de Demandas Repetitivas se faz necessária tendo em vista que os critérios empregados para a solução da questão poderão (deverão) ser transformados em regra geral para situações fáticojurídicas idênticas.

Tal situação também é destacada por Cavalcanti (2016, p. 257):

O NCPC deu muita importância à participação do amicus curiae no IRDR. Tanto é que previu uma exceção à regra geral de que os amici curiae não têm legitimidade para interpor recursos, salvo embargos de declaração. Como será visto adiante, o art. 138, $\S 4 .^{\circ}$, do NCPC estabeleceu ampla legitimidade para o amicus curiae recorrer da decisão que julgar o incidente processual coletivo. No IRDR, portanto, os amici curiae podem interpor todos os recursos cabíveis e não apenas os embargos de declaração. Não se aplica a regra geral restritiva prevista no $\S 1 .^{\circ}$ do art. 138.

Dentre dessa ótica, resta claro que o legislador procurou garantir o amplo debate e a participação democrática dos interessados na fixação da tese. Por consequência, entende-se que tal comportamento também deveria ser direcionado a fase de admissão diante das 


\section{O JUÍZO DE ADMISSIBILIDADE DO INCIDENTE DE RESOLUÇÃO DE DEMANDAS REPETITIVAS: CRÍTICA A AUSÊNCIA DE CONTRADITÓRIO EM FACE DA SOCIEDADE DA INFORMAÇÃO}

consequências do juízo positivo de admissibilidade já apontadas: suspensão dos processos, preclusão e irrecorribilidade da decisão.

Assim, a valorização do instituto depende de eventual alteração legislativa para que expressamente seja oportunizado o contraditório prévio ou através de construção jurisprudencial para garantir a eficácia do art. $5^{\circ}, \mathrm{LV}$ da $\mathrm{CF} / 88$ no juízo de admissibilidade do Incidente de Resolução de Demandas Repetitivas.

\section{Conclusão.}

O Incidente de Resolução de Demandas Repetitivas ainda é um estranho que precisa ser construído (ou aprimorado) pela doutrina e a jurisprudência pátria. Considerando a sua influência alemã, bem como, as próprias críticas ao processo de importação do instituto resta claro que os precedentes do direito alemão não se aplicam integralmente ao ordenamento jurídico brasileiro.

Sendo um procedimento bifásico e a existência de inúmeros requisitos positivos e negativos de admissibilidade, conforme demonstrado, a fase de admissão não deve ser considerada como mero requisito processual prévio a fixação da tese jurídica. Ao revés, diante dos efeitos processuais já gerados pelo juízo positivo de admissibilidade a participação e postura das partes e do Poder Judiciário é extremamente relevante.

Verificada a omissão legislativa quanto ao contraditório antes do julgamento da admissão, tem-se que tal situação não encontra amparo constitucional diante da importância deste instituto na (nova) tentativa de mitigar a dispersão jurisprudencial. Diante desta premissa e analisado dentro do atual contexto da Sociedade da Informação, defende-se que a valorização do Incidente de Resolução de Demandas Repetitivas e a efetivação do Direito à Informação e ao Acesso à Informação depende de um contraditório substancial, inclusive na fase de admissão do recurso.

Afasta-se eventual arguição de que o contraditório atenta com a razoável duração do processo eis que os mecanismos de tecnologia da informação e comunicação, em especial, a virtualização do processo judicial permitem a rápida e eficiente participação dos atores processuais. Dentro de um contexto de excesso de informação, o contraditório prévio, 
inclusive auxilia no processo de depuração da imensidão de dados disponíveis (nem sempre satisfatoriamente organizados) e permitem um julgamento mais seguro e eficiente.

Assim, pode-se afirmar que a participação das partes na Sociedade da Informação é ágil, útil e necessária para condução da melhor decisão judicial possível no juízo de admissibilidade do Incidente de Resolução de Demandas Repetitivas. Ocorre, todavia, que tal situação somente será efetiva com eventual alteração legislativa para que expressamente seja oportunizado o contraditório prévio ou através de construção jurisprudencial para garantir a eficácia do art. $5^{\circ}, \mathrm{LV}$ da CF/88 no juízo de admissibilidade do Incidente de Resolução de Demandas Repetitivas. Não existindo espaço para mitigação do contraditório no sistema processual, o processo de maturação do Incidente também depende da devida atenção a dialética na fase de admissibilidade, como proposto.

\section{Referencias bibliografias.}

ABBOUD, Georges; CAVALCANTI, Marcos de Araújo. Inconstitucionalidades do incidente de resolução de demandas repetitivas (IRDR) e os riscos ao sistema decisório. Revista de Processo | vol. 240 | Fev/ 2015

BRASIL. Código de processo civil e normas correlatas. - 7. ed. - Brasília : Senado Federal, Coordenação de Edições Técnicas, 2015, Disponível em

<http://www.senado.gov.br/senado/novocpc/pdf/Anteprojeto.pdf>, acesso em 30.1.2018

BUENO, Cássio Scarpinella. Manual de Direito Processual Civil. São Paulo: Saraiva, 2016.

CABRAL, Antônio do Passo. A escolha da causa-piloto nos incidentes de resolução de processos repetitivos. Revista de Processo, vol. 231/2014, p. 201-223, mai/2014.

CASTRO MENDES, Aluisio Gonçalves de. INCIDENTE DE RESOLUÇÃO DE DEMANDAS REPETITIVAS - Sistematização, análise e interpretação do novo instituto processual. Forense - 2017 - $1^{\mathrm{a}}$ edição

CASTRO MENDES, Aluisio Gonçalves de; TEMER, Sofia Orberg. ART. 976. In: STRECK, Lenio Luiz; NUNES, Dierle; CUNHA, Leonardo (orgs.). Comentários ao Código de Processo Civil. São Paulo: Saraiva, 2016. p. 1271

CAVALCANTI, Marcos Araujo. Incidente de resolução de demandas repetitivas. $1^{\text {a }}$ Edição. São Paulo: Revista dos Tribunais, 2016 (Coleção Liebman/ coordenadores Teresa Arruda Alvim Wambier, Eduardo Talamini)

CINTRA, Antônio Carlos de Araújo; GRINOVER, Ada Pellegrini; DINAMARCO, Cândido Rangel. Teoria geral do processo. $30^{\mathrm{a}}$ ed. São Paulo: Malheiros, 2014.

MOREIRA, José Carlos Barbosa. Efetividade do processo e técnica processual. Temas de Direito Processual - sexta série. São Paulo: Saraiva, 2016.

MARINONI, Luiz Guilherme. Incidente de resolução de demandas repetitivas: decisão e questão idêntica x precedente. São Paulo: revista dos Tribunais, 2016. 


\section{O JUÍZO DE ADMISSIBILIDADE DO INCIDENTE DE RESOLUÇÃO DE DEMANDAS REPETITIVAS: CRÍTICA A AUSÊNCIA DE CONTRADITÓRIO EM FACE DA SOCIEDADE DA INFORMAÇÃO}

MANCUSO, Rodolfo de Camarfo. Incidente de resolução de demandas repetitivas: a luta contra a dispersão jurisprudencial excessiva. São Paulo: Revista dos Tribunais, 2016.

NUNES, Dierle. O IRDR do Novo CPC: um estranho que merece ser compreendido. Disponível em: < http://justificando.com/2015/02/18/o-irdr-novo-cpc-este-estranhoquemerece-ser-compreendido/>

SANTOS, Welder Queiroz dos. Direito processual civil: princípio do contraditório e vedação de decisão surpresa / Welder Queiroz dos Santos. - 1. ed. - Rio de Janeiro: Forense, 2018.

SILVEIRA, Domingos Sávio Dresch da. Considerações sobre as garantias constitucionais do acesso ao Judiciário e do contraditório. In: OLIVEIRA, Carlos Alberto Alvaro (Org.). Elementos para uma nova teoria geral do processo. Porto Alegre: Livraria do Advogado, 1997.

THEODORO JÚNIOR, Humberto. Celeridade e efetividade da prestação jurisdicional: insuficiência da reforma das leis processuais. Disponível em: <http://www.abdpc.org.br/artigos/artigo51.htm>.

VIAFORE, Daniele, As semelhanças e as diferenças entre o procedimento-modelo alemão Musterverfahren e a proposta de um "incidente de resolução de demandas repetitivas no P1 8.046/2010. Revista de Processo São Paulo, v.38, n.217, p. 257-308, mar., 2013. 